\title{
LA GUERRA DEL RECIBO DEL AGUA Una movilización popular atípica en el área metropolitana de Barcelona, 1992-2002
}

\author{
JOAQUÍM SEMPERE \\ Universidad de Barcelona
}

PALABRAS CLAVE ADICIONALES

Proactivo, Capital social, Estructuras de movilización.

\section{ADDITIONAL KEYWORDS}

Proactive, Social Capital, Mobilization Structures.

RESUMEN. El trabajo describe y analiza una lucha que durante diez años movilizó en Cataluña a más de 200.000 personas en un acto de insumisión fiscal contra los impuestos del recibo del agua. Esta insólita protesta, aunque meramente reactiva en sus orígenes, incorpora luego elementos proactivos que se concretan en aspiraciones de democracia participativa y en la defensa de criterios fiscales de carácter ambiental y social, y muestra síntomas de la emergencia de una nueva sociedad civil. Ilustra los conceptos de "capital social", "intelectual colectivo" y "estructuras de movilización".

SUMMARY. This article describes and analyes the mobilization in Catalonia during ten years of about 200.000 persons in a collective action of fiscal disobedience azainst the taxes associated with the payment of water consumption. This unaccustomed protest, even if only reactive at the beginning, becomes later proactive, namely with aspirations to participative democracy and the advocacy of fiscal standars, in environmental and social issues, and shows signs of the emergence of a new civil society. It embodies the concepts "social capital", "collective intellectual" and "mobilization structures".

\footnotetext{
* Este trabajo es un producto lateral de la contribución del autor a la investigación dirigida por Salvador Giner sobre "La ciudadanía proactiva" (proyecto I+D del Ministerio de Ciencia y Tecnología 2001-2003). Agradezco a la becaria Anna París su ayuda en el trabajo de transcripción de las entrevistas y a Andrés Naya sus comentarios sobre el último borrador.

E-mail: j.sempere@ub.edu
}

Revista Internacional de Sociología (RIS)

Tercera Época, $\mathrm{N}^{\circ}$ 38, Mayo-Agosto, 2004, pp. 169-187. 


\section{RIS}

La "guerra del recibo del agua" ha recibido poca atención fuera de Cataluña $e$ incluso en Cataluña debido al escaso interés que por ella mostraron los medios de comunicación, pese a sus dimensiones excepcionales: 80.000 familias, que representan unas 200.000 personas, practican la objeción fiscal (o "huelga fiscal") y se niegan a pagar la factura del agua durante diez años. Probablemente el escaso interés se debe a la condición socialmente marginal de sus protagonistas, que en su inmensa mayoría pertenecían a la clase obrera industrial del cinturón de Barcelona, con predominio de jubilados y pensionistas. Otra explicación es que los partidos políticos, las dos centrales sindicales mayoritarias (CCOO y UGT) y dos asociaciones de consumidores, que al principio apoyaron la movilización, se retiraron de ella cuando las administraciones públicas implicadas aceptaron dialogar, aunque la Confederación vecinal rechazara el acuerdo propuesto. La lucha prosiguió, pese a ello, durante ocho años más, bajo la dirección êxclusiva de las Asociaciones de Vecinos, que la habían encabezado desde el principio, pero es evidente que las instituciones políticas y sociales mencionadas tienen mayor capacidad que el movimiento vecinal para aparecer en los medios de comunicación y dar visibilidad a las acciones colectivas. El movimiento vecinal, abandonado a su suerte, resistió sorprendentemente durante años, pero pagó su soledad con el silencio clamoroso de los medios de comunicación.

Esta lucha insólita y muy localizada tiene peculiaridades notables que la hacen merecedora de mayor atención que la que ha recibido hasta ahora. Ofrece, entre otras cosas, un ejemplo de acción reactiva que se transforma en proactiva gracias a la acción consciente de su dirección colectiva: las asociaciones de vecinos. Ofrece también un ejemplo de capital social acumulado en estas asociaciones, que, gracias a los vínculos de confianza establecidos durante años con el vecindario, les facilita convertirse en representantes "naturales" de los vecinos cuando éstos entran en conflicto con unas compañías de agua y unas administraciones públicas que perciben como hostiles y ajenas. Ofrecen asimismo una concreción muy palpable de intelectual colectivo que se relaciona, a través de un proceso básicamente asambleario, con las decenas de miles de vecinos movilizados. Finalmente, permite calibrar hasta qué punto el movimiento vecinal asumió los componentes medioambientales implícitos en una lucha por la gestión de un recurso natural escaso como es el agua.

\section{EL CÓMO Y EL PORQUÉ DE LA GUERRA DEL RECIBO DEL AGUA}

La lucha empezó en octubre de 1991 cuando algunos vecinos (sobre todo vecinas) de L'Hospitalet de Llobregat, Badalona y Ciutat Badia, observando que el recibo del agua había subido repentinamente entre un 50 y un $100 \%$, acuden a las asociaciones de vecinos de sus respectivos barrios pidiendo asesoramiento sobre lo que consideran un abuso y buscando un marco organizativo para iniciar una 
protesta. Las asociaciones de vecinos (AA.VV.) de estos barrios asumen la voluntad de protesta e intentan darle forma y extenderla a otros barrios de la conurbación barcelonesa, llevándola a la Confederación de Asociaciones de Vecinos de Cataluña (CONFAVC). En pocas semanas los dirigentes vecinales comprueban que el malestar es general, sobre todo entre la población trabajadora de menores ingresos y entre jubilados y pensionistas. Durante el año 1992 llegan a unos 150 los barrios incorporados a la protesta bajo la dirección de sus AAVV, de las federaciones municipales de AAVV y de la Confederación catalana (DA, 1996: 3).

Como subrayan los dirigentes, no fueron las AAVV las que tomaron la iniciativa, sino los vecinos:

“En L'Hospitalet [de Llobregat] no fuimos la asociación de vecinos la que propuso la campaña, sino los propios vecinos los que empujaron a entrar en esa campaña. Ešo nos ha dado una cierta fuerza a todos los niveles. No hemos 'vendido' nada a los vecinos, sino que han sido ellos los que han dicho 'hay que hacer algo", dice el presidente de la Federación local de AAVV, aunque señala que no se puede generalizar: "No ha sido el caso de otras localidades, donde han sido las asociaciones [las] que han llamado a los vecinos a entrar en la campaña" [MP 4]. ${ }^{1}$

$\mathrm{Al}$ comienzo los dirigentes tomaron incluso cierta distancia ante el problema: no veían claro qué significaba aquel aumento inexplicable de la factura del agua ni cómo debían reaccionar. El elemento de espontaneidad de la movilización fue, pues, tan grande que arrastró a las propias AAVV, que eran las organizaciones más cercanas a los interesados y más vinculadas a sus intereses. En este caso la "movilización de los recursos" se plasma en la utilización por los vecinos descontentos del instrumento más a mano, las AAVV, que aparecen como la organización del movimiento (McCarthy y Zald, 1977). Pero ilustra también que, para explicar la acción colectiva, la teoría de la movilización de los recursos debe tener la flexibilidad suficiente para cargar el acento, unas veces, más en la espontaneidad y, otras, más en la iniciativa de la organización del movimiento social.

Como en toda acción colectiva de protesta, una primera fase consistió en definir y dar forma y expresión verbal al motivo de la protesta, lo cual exigía un análisis de las distintas partidas del recibo y una comparación con el recibo anterior. Se comprobó que, además de aumentos que oscilaban entre el $5,2 \%$ y el $50,7 \%$ de las partidas antes existentes en el recibo del agua (véase $V C$, enero 1992: 5), se añadían al mismo un conjunto de cánones y tasas que antes no figuraban en él. Dos de ellos iban a parar a la Generalitat (el "complemento para el mantenimiento de

\footnotetext{
${ }^{1}$ Las referencias remiten a las transcripciones de las entrevistas de cinco dirigentes y activistas vecinales.
} 
RIS

REVISTA INTERNACIONAL DE SOCIOLOGIA

No 38, MAYO-ACOST0, 2004

JOAQUIM SEMPERE

la red básica del agua" y el "canon de infraestructura hidráulica"), y un tercero a la Entidad Metropolitana del Medio Ambiente (EMMA) (la "tasa de eliminación de residuos sólidos urbanos"). En el proceso de análisis del nuevo recibo, los vecinos adquirían conciencia, por vez primera, de que pagando el agua pagaban al mismo tiempo unas cantidades por conceptos extraños, a veces totalmente ajenos al ciclo del agua. Descubrían que, aparte de los tres nuevos tributos, habían estado pagando otras cuatro partidas a distintas administraciones: un "canon de garantía de suministro" (EMMA); una "tarifa de saneamiento" (Generalitat); una "tasa de alcantarillado" (ayuntamientos); unos "cánones y arbitrios" (que desaparecían del nuevo recibo).

Descubrían también que unas sociedades mercantiles (las compañias suministradoras del agua) ${ }^{2}$ eran las encargadas de recaudar los tributos correspondientes a las administraciones públicas. En el nuevo recibo el consumo de agua representaba aproximadamente el $43 \%$ y los tributos el $57 \%$, que correspondían a las administraciones siguientes: $30 \%$ a la Generalitat; $13 \%$ a la EMMA (8\% para tratamiento de residuos sólidos); $11 \%$ a los ayuntamientos, y $3 \%$ al Estado central.

Cuando algunas AAVV habían empezado a recoger firmas de protesta, la CONFAVC se reunió con los sindicatos Comisiones Obreras y UGT y dos organizaciones de consumidores de Cataluña (OCUC y ACPB) para constituir una "Mesa contra el Precio del Agua", que se convertirá en "Plataforma [unitaria] de Entidades contra los Aumentos Abusivos de los Impuestos sobre el Agua", y lanzar una recogida masiva de firmas en torno a tres puntos: (1) ningún aumento de los cánones impositivos, (2) eliminación de todas las tasas del recibo del agua, y (3) financiación de las infraestructuras a cargo de los presupuestos públicos $(V C \text { enero, 1992) })^{3}$. La reivindicación se había depurado: no se reclamaba sólo pagar menos, sino también transparencia en la recaudación tributaria y equidad (considerando las infraestructuras hidráulicas como asunto de interés general que no debía asociarse sólo a los consumos domésticos de agua). Entre enero y marzo de 1992 se recogieron más de 70.000 firmas. Todos los partidos políticos del arco parlamentario catalán (CDC, UD, PSC-PSOE, PP, IC y ERC), pendientes de las elecciones, adquirieron compromisos sobre el tema que luego no respetarían.

\footnotetext{
${ }^{2}$ Las compañía eran las siguientes: Aguas de Barcelona (AGBAR), SAUR, SOREA, Aguas del Prat y Aguas Molins. Todas ellas estaban participadas por la Sociedad General de Aguas de Barcelona (SGAB), empresa controlada, en el momento del conflicto, a la par por el grupo multinacional francés Dumez-Lyonnaise des Eaux y la Caixa d'Estalvis i Pensions de Barcelona.

${ }^{3}$ Dos años y medio más tarde, los objetivos de la campaña venían definidos así en la revista de la Federación de Asociaciones de Vecinos de Barcelona (FAVB): $a$ ) supresión de las leyes 4/90 y
} 


\section{LA OBJECIÓN FISCAL Y SUS CONSECUENCIAS PRÁCTICAS}

La movilización da un salto cualitativo al optar en febrero de 1994 por una forma de desobediencia civil: la objeción fiscal. El planteamiento es el siguiente: los usuarios sólo queremos pagar el coste del agua, no unos tributos que nos parecen abusivos. Así se les plantea a las compañías. Pero éstas no aceptan cobrar sólo una parte del recibo porque tienen unos compromisos con las administraciones públicas. Las AAVV deciden entonces ingresar el coste del agua (más IVA) en cuentas bancarias intervenidas notarialmente a nombre de la Plataforma unitaria. Así se hace pública la voluntad de pagar los consumos y se previene la acumulación de deudas demasiado cuantiosas para los participantes. Cada mes, el notario ofrecía el dinero ingresado a las compañías. Éstas se negaron a aceptar el dinero hasta el 14 de octubre de 1994. Entonces cambiaron de opinión al ver que la protesta no era una broma por la magnitud de las sumas ingresadas acumuladas: unos 1.200 millones de pesetas por aquellas fechas ( $V C$, noviembre 1994).

La Confederación, antes de lanzar la consigna de objeción fiscal, había consultado a comienzos de 1993 al Fiscal General de Cataluña para saber si, en caso de no pagar los impuestos, las compañías podían cortar el agua. Se trataba de evitar medidas que pudieran llevar a los vecinos al desastre. El informe favorable de la Fiscalía hizo que se optara por la vía de la objeción. Se aceptó la propuesta de la Sociedad General de Aguas de Barcelona de que "la Caixa" (que es accionista principal de la Sociedad) se hiciera cargo de los ingresos. Esta entidad de crédito editó un impreso de ingresos especial, con una copia para que el movimiento vecinal pudiera llevar el control.

Dejar de pagar e ingresar el dinero en cuentas bancarias supuso un esfuerzo organizativo gigantesco para las AAVV. Los vecinos que se sumaban a la protesta debían dar los pasos siguientes: (1) desdomiciliar el pago del agua - las AAVV facilitaron los impresos para hacerlo-; (2) cuando se recibía la factura, ir a la Asociación de Vecinos con ella para hacer los cálculos correctos de lo que debía pagarse; (3) ir a la entidad de crédito a ingresar en la cuenta de la Plataforma unitaria el coste del agua más IVA; (4) volver a la Asociación de Vecinos con el volante de la entidad de crédito para que la Plataforma pudiese llevar el control de todos los pagos. Teniendo en cuenta que la consigna de no pagar se extendió

5/90 del Parlamento de Cataluña y nueva legislación que simplifique la gestión del ciclo del agua y cree una autoridad única; $b$ ) un único impuesto de inversiones en lugar de tres; $c$ ) eliminación de los mínimos en materia de impuestos para las primeras residencias; $d$ ) retirada de la factura del agua de todas las tasas e impuestos ajenos al ciclo del agua; $e$ ) que las futuras subidas de tarifas estén por debajo del IPC; $f$ ) revisión de la política tarifaria; $g$ ) tasa de saneamiento mayor para quienes más contaminan, y no en función del consumo doméstico de agua; $h$ ) volver al valor de 1990 del precio final del metro cúbico de agua ( $V C$, noviembre 1994: 3). 
RIS

REVISTA INTERNACIONAL DE SOCIOLOCÍA

№ 38, MAYO-AGOSTO, 2004

JOAQUIM SEMPERE

rápidamente hasta alcanzar las 70.000 familias, cifra que fue aumentando hasta las 80.000 , esto representó para las AAVV un reto importante: la puesta en pie de una infraestructura totalmente nueva. En casi todos los casos se pudo resolver con trabajo voluntario y gratuito de los miembros asociados, aunque en algunos casos hubo que recurrir a personas pagadas para cubrir las tareas de cálculo, asesoramiento, archivo, control, etc.

Para AN, presidente de la AV del Buen Pastor (barrio industrial de la capital catalana), el trabajo de papeleo fue fundamental para asegurar la marcha de la campaña. Para este trabajo la $\mathrm{AV}$ contó con no más de 4 ó 5 personas que se iban turnando para asesorar a los vecinos y vecinas, ayudarles a rellenar los impresos y explicarles los trámites necesarios. Además, había que recoger y archivar los volantes acreditativos del pago de cada vecino o vecina en la cuenta bancaria común. A veces, cuenta $A N$, se juntaban hasta 200 personas y había que atenderlas. AN estima que él y los activistas más abnegados dedicaban unas 4 ó 5 horas diarias a estas tareas. En L'Hospitalet las tareas de la campaña recayeron, según MP, en 13 personas, "prácticamente fijas, que eran más o menos las que formaban la junta", más "un equipo de colaboradores que estaban otros días [...] más o menos esporádicos". Para llevar esa campaña, a su juicio, "se necesitan un mínimo de 15 ó 20 personas con una cierta dedicación. El gran problema que nosotros teníamos era que todos tenemos que acudir al trabajo, todo lo hacemos de una forma voluntaria y a partir de una hora determinada. Entonces teníamos que buscar personas que tenían turnos de trabajo para que por las mañanas estuvieran disponibles [...] y también hemos hecho uso de personas jubiladas y prejubiladas". En toda la campaña hubo una participación bastante amplia de vecinos y vecinas que de una u otra forma trabajaron voluntariamente: "A nivel de L'Hospitalet no ha habido nadie que, digamos, estuviera asalariado o percibiendo algo, un salario" [MP 10-11]. En otras localidades, en algunos barrios, sí hubo personas que cobraban por el trabajo hecho, pero pocas; $y$ en este caso, solían ser gente de la propia $\mathrm{AV}$, que dedicaba muchas más horas que las contratadas (como MF, del barrio barcelonés de Sant Antoni).

En este caso, las AAVV como organizaciones del movimiento social, hicieron valer su carácter organizado como recurso útil para desarrollar unas tareas contables $\mathrm{y}$ administrativas que resultaban necesarias para que la reivindicación llegara a buen puerto.

La "guerra del recibo del agua" plantea interrogantes sobre el papel de los expertos. Los movimientos sociales de nuestros días, a diferencia de los de sociedades preindustriales, menos complejas, suelen requerir la intervención de personas con capacitaciones intelectuales o tecnocientíficas especializadas. Si en los motines de subsistencia (las protestas contra los acaparadores y especuladores $\mathrm{y}$ otras luchas sociales de los siglos XVII y XVIII en Europa) bastaban nociones comunes de ética económica que estaban al alcance de cualquier artesano o cam- 
pesino ${ }^{4}$, en las luchas de una sociedad compleja y tecnificada los movimientos de protesta necesitan especialistas que den forma tanto al malestar, como a las soluciones reivindicadas, y que transmitan al movimiento los conocimientos requeridos para dar formalidad - técnica, jurídica, etc.-a la protesta. Pero también ocurre que, a veces, los propios dirigentes sociales asumen tareas de dirección técnica y jurídica: ello es posible por el elevado nivel de educación formal que poseen muchos de esos dirigentes en la actual sociedad de la información. Los dirigentes de las AAVV entrevistados destacan que el papel de los expertos en todo el proceso fue mínimo. Fueron ellos mismos, los dirigentes y activistas, los que asumieron todas las tareas, desde la información hasta la gestión. Sólo se apeló a algunos abogados y fiscales para conocer el marco jurídico general y los riesgos potenciales.

Hasta que se comprobó que la negativa a pagar no tenía como consecuencia el corte del suministro de agua, había que prever una respuesta a dicho riesgo. $\mathrm{La}$ respuesta fue manipular la llave de paso con objeto de restablecer el suministro en caso de que la empresa lo cortase. Esta infracción quedaba legitimada por la voluntad de los consumidores de pagar - evidenciada por el ingreso del importe en la cuenta corriente de la Plataforma-y por el hecho de ser el agua un bien de primerísima necesidad. La Plataforma reclutó fontaneros voluntarios (los llamados "fontaneros populares") dispuestos a intervenir en la llave de paso si hacía falta, y hasta se organizaron cursillos de fontanería en algunos barrios.

"[...] incluso nos proporcionaron unas llaves un poco especiales que tiene la compañía para hacer el cierre, con rosca izquierda, para sacar el tapón que ellos ponen. $Y$ entonces, con una serie de artimañas, nos servía para restituir el servicio. En fin, hicimos un cursillo acelerado, nos dieron llaves de éstas y nosotros aquí, en Sant Josep [L'Hospitalet] nos quedamos bastante solos durante el año 2001, temiendo que volvieran [a cortar el agua]. Y fruto de estos cortes habíamos hecho equipos de vecinos y teníamos turnos de mañana y de tarde, [para] en caso de cualquier corte [...] restituir [el suministro] rápidamente. No hubo necesidad [...]. La compañía se comportó correctamente" [MP 10].

\section{LAS ASOCIACIONES DE VECINOS SE QUEDAN SOLAS}

La objeción fiscal era, obviamente, una forma de presión sobre las administraciones públicas. Pero éstas no se daban por enteradas. El 20 de febrero de 1994

\footnotetext{
${ }^{4}$ Véanse las observaciones del historiador Edward P. Thompson (1979) sobre la "economía moral de la multitud" en la Gran Bretaña del siglo XVIII.
} 
RIS

REVISTA INTERNACIONAL DE SOCIOLOCIA

№ 38, MAYO-AGOST0, 2004

JOAQUIM SEMPERE

tuvo lugar una manifestación importante en la calle, ${ }^{5}$ en la que participaron entre quince y treinta mil personas (según las fuentes), y que se dirigió a la Plaza de Sant Jaume, donde se ubican, frente a frente, la Generalitat y el Ayuntamiento de Barcelona. En aquellos momentos la campaña era protagonizada ya por unos 200 barrios de todo el área metropolitana, y durante el mismo año se contabilizan unas 1.500 asambleas y reuniones y unos cobros acumulados en la cuenta de la Plataforma de unos 1.200 millones de pesetas ( $V C$, noviembre 1994).

Esta decisión de las compañías es todavía más significativa si se tiene en cuenta que poco antes, el 29 de septiembre, se había firmado un "acuerdo de paz". Las administraciones habían accedido finalmente a negociar con la Plataforma unitaria, con la presencia de todos sus componentes: los sindicatos Comisiones Obreras y UGT, las organizaciones de consumidores, la CONFAVC y los partidos políticos. La CONFAVC se negó a firmar y, reunida pocos días después, el 3 de octubre, decidió aprobar la negativa de sus representantes y no ratificar el acuerdo, aduciendo que el documento presentado por las administraciones era una lista de intenciones sin compromisos concretos, que la reducción del precio del agua propuesta no era suficiente y que establecía un plazo demasiado breve para devolver los tributos no pagados. Esta decisión de la Confederación es un hito fundamental en la lucha, porque desde aquel momento las AAVV se quedaron solas, sin la compañía y sin el apoyo de las otras organizaciones. Se puede suponer sin temor a errar que esta ruptura de la Plataforma indujo a las administraciones a pensar que el movimiento popular quedaría debilitado y a adoptar una postura aún más cerril y menos dialogante que en los tres años anteriores. La sorpresa fue que el movimiento no cedió, y había de proseguir 7 años más sin desfallecer. Un primer síntoma de esta fuerza fue la manifestación del 23 de octubre de 1994, que reunió en la Plaza de Sant Jaume entre diecisite y treinta mil personas. El apoyo de las organizaciones formales se reveló prescindible.

La soledad de los movilizados - abandonados por partidos, sindicatos y organizaciones de consumidores - no puso fin a la lucha, pero puso en evidencia que una parte importante de la fuerza de un movimiento procede de sus alianzas con sectores y organizaciones sociales capaces de influir en el sistema político. El poder no se atreve entonces a ser demasiado beligerante con organizaciones potentes y reconocidas como las mencionadas. A falta de tales alianzas, el movimiento pierde capacidad negociadora y visibilidad para la opinión pública. La guerra del recibo del agua experimentó estas debilidades: la solución se demoró muchísimos años y sus protestas aparecieron con poca frecuencia y escaso apoyo y simpatía en los medios de comunicación. El movimiento se aisló del conjunto de la sociedad.

\footnotetext{
${ }^{5}$ En marzo de 1993 se habían manifestado ya unas 5.000 personas, con casi absoluto predominio obrero y ausencia de los activistas de capas medias habituales en estas movilizaciones en Cataluña (Recio 1993: 21).
} 


\section{LOS PLANTEAMIENTOS MEDIOAMBIENTALES EN LA GUERRA DEL RECIBO DEL AGUA}

En una primera aproximación cabe decir que el nuevo recibo del agua contra el que se movilizan los vecinos parece tener una justificación ecológica: hay que ahorrar agua e invertir en infraestructuras hidráulicas. Por esto se aplicarían ciertas tasas proporcionalmente al consumo de agua y se recaudarían tributos vinculados al ciclo del agua. Pero la verdad es que el nuevo recibo no respondía a una visión realmente consciente de los problemas del ciclo del agua, ni a la intención de incorporar criterios ambientalistas. "En muchos casos se han aplicado impuestos teóricamente finalistas, como el canon de infraestructuras hidráulicas, que en la práctica no conducen a ningún tipo de inversión y que se estarán utilizando para financiar gastos públicos normales. En otros casos se han introducido partidas que no tienen nada que ver con el consumo de agua, como es el caso de la tasa de basuras, que anteriormente se cobraba directamente por la Administración. [...] Más que la racionalidad en el consumo del agua, lo que parece haber predominado ha sido la capacidad recaudatoria. Es evidente que siempre es más fácil cobrar impuestos cuando éstos se asocian a otras operaciones que cuando se hace directamente" (Recio, 1993: 20-21).

¿Y los vecinos? En una primera fase del proceso no hay conciencia ambiental, ni en los vecinos ni en los dirigentes. La convergencia - y posterior colaboración - con los ecologistas empieza cuando la plataforma Barcelona estalvia energia ${ }^{6}$ exigió, en una moción presentada en noviembre de 1992 al consistorio barcelonés, que la tasa de basuras se separase del recibo del agua y se graduase en función de la cantidad de residuos sólidos urbanos generada por cada persona $o$ empresa (Tello 1994: 18). Durante la campaña de objeción fiscal, los ecologistas estuvieron presentes en distintos niveles de la lucha, discutiendo con los dirigentes y con los vecinos en asambleas y tratando de incluir criterios de sostenibilidad ecológica a los criterios económicos y de equidad social presentes en las reivindicaciones del movimiento vecinal. Hubo diálogo con los órganos de dirección de las AAVV, tanto en el nivel de Confederación y de federaciones locales como en el nivel de barrio, y participación ecologista a veces en las asambleas de vecinos.

MP confiesa que todos aprendieron en el tema del agua, incluidos "todos aquellos que estábamos metidos en la asociación de vecinos", que al principio "íbamos simplemente por el tema economicista". Este aprendizaje no fue de laboratorio, sino que tuvo lugar en medio de un "proceso de asambleas muy continuado para ir explicando. [...] los

\footnotetext{
6 "Barcelona ahorra energía": plataforma compuesta por grupos ecologistas (Acció Ecologista, DEPANA, CEPA, Amics de la Bici, Amics de la Terra, Col-lectiu Agudells, Ecologistes i Pacifistes de Nou Barris, entre otros), la FAVB, CCOO y USTEC (sindicato de trabajadores de la Enseñanza).
} 


\section{RIS}

propios debates iban enseñando a los propios ciudadanos [...]. De ahí se fue haciendo un debate muy dinámico, porque incluso hemos tenido encuentros y contactos a nivel de L'Hospitalet con grupos ecologistas, más que nada para demostrar que nosotros no éramos un movimiento anti-impuestos, ni mucho menos". Reconoce, sin embargo, que no contaron con expertos tanto como hubieran debido: "quizás teníamos que haber aprendido más, consultar más antes de haber empezado la campaña; lo que ocurre es que la campaña estaba avanzada, estaba ahí, había que darle respuesta día a día" [MP 6].

La reclamación de transparencia en las distintas partidas del recibo del agua tiene también una significación ambientalista, aunque tardara en hacerse consciente en el movimiento vecinal. Para lograr conductas ecológicamente aconsejables, hay que conseguir que los consumidores y usuarios paguen los costos ambientales - a menudo ocultos-y sepan que los pagan y por qué. Este es un principio básico para diseñar cualquier ecotasa. Como dice Enric Tello, "[p]ara ser a la vez justas y eficaces las ecotasas deben aplicarse con transparencia y proporcionalidad. Transparencia, para que la información que se quiere transmitir llegue con claridad al sujeto impositivo sobre cuyas decisiones se quiere influir (en este sentido, 'camuflar' la tasa de basuras domésticas en el recibo del agua es un ejemplo patente de lo que no debe hacerse). Proporcionalidad, para que la carga se corresponda con la responsabilidad efectiva del sujeto impositivo en la situación que se quiere cambiar. Por eso, entre las condiciones que una izquierda verde debe poner para legitimar futuras ecotasas debemos añadir que la tasa recaiga siempre en el sujeto responsable, y en la proporción que se corresponda con esa responsabilidad" (Tello, 1994: 20-21).

El resultado del diálogo entre movimiento vecinal y ecologistas fue reivindicar varias medidas que plasmaban criterios de ahorro del agua, de transparencia (fomentadora de la conciencia y las buenas prácticas ecológicas) y de equidad. Se incorporaron los puntos siguientes: 1) quitar del recibo del agua la tasa de basuras porque no tenía nada que ver con el ciclo del agua; 2) abaratar el bloque de los primeros 100 litros por persona y día (considerando que el agua es un bien de primera necesidad) y aumentar progresivamente los bloques siguientes para desincentivar el despilfarro; y 3) eliminar el umbral mínimo, que perjudica a quien consume muy poco, e incluir en el cálculo de bloques el número de personas de cada hogar para no penalizar a las familias numerosas.

En 1996 la guerra del recibo del agua da un salto cualitativo en materia ambiental porque ese año el movimiento vecinal de toda España asume como objetivo valioso el ahorro de agua después de varias sequías graves. La redacción de La Veu del Carrer escribe lo siguiente: "Las asociaciones de vecinos de todo el Estado Español estamos realizando una campaña con el objetivo de disminuir el consumo de agua. No podemos descuidar un tema de la máxima importancia porque en los últimos meses las lluvias hayan aumentado. El ahorro de agua es 
ahora fundamental, si tenemos en cuenta que España es el segundo país europeo que más agua consume por habitante, pese a que es uno de los más secos [...] desde la FAVB nos parece importante esta campaña; puede ser un complemento necesario a la lucha que venimos desarrollando contra los impuestos abusivos en el recibo del agua". Y añade: "Es urgente un cambio de hábitos", reproduciendo un decálogo de "medidas para ahorrar el consumo de agua en el uso doméstico":

1. Es preferible ducharse que bañarse;

2. Cerrar el grifo cuando nos enjabonamos durante la ducha;

3. Cerrar el grifo mientras nos lavamos los dientes;

4. Poner el tapón del lavabo cuando nos lavamos las manos;

5. Reducir de 10 a 4 litros la capacidad de la cisterna de los wáteres;

6. Utilizar lavadora y lavaplatos sólo cuando están llenos;

7. No lavar los platos con el grifo abierto;

8. No lavar el coche cada semana, y hacerlo con un cubo o en estaciones de utolavado;

9. Poner difusores en los grifos;

10. Incorporar especies vegetales menos consumidoras de agua en los jardines, y controlar el riego.

La sequía de años anteriores contribuyó a esta toma de conciencia en España entera. En cualquier caso, este pronunciamiento del movimiento vecinal de toda España es asumido en el área metropolitana barcelonesa justo en plena lucha del recibo del agua y marca un hito más en la toma de conciencia de los problemas que plantea este recurso natural vital, su consumo y gestión.

En 1998 el movimiento vecinal había asumido ya un programa muy maduro y completo en cuanto a criterios ecológicos. Antes del verano de 1998, la CONFAVC fue convocada por la Generalitat con la demanda de consensuar un proyecto de Ley del Agua que se pudiera incorporar a los Presupuestos Generales para entrar en vigor el primero de enero de 1999. Según palabras del entonces vicepresidente de la Federación barcelonesa, Andrés Naya, "[p]arecía que llegábamos a un acuerdo en criterios generales, pero luego la letra de los documentos no los recogía. Pasaba el tiempo y decidimos enviar una propuesta", que se resumía así, en palabras de Naya: “[1] La recaudación final no disminuía, pero [2] garantizábamos que 100 litros por persona y día tenían un precio político. [3] El despilfarro había que pagarlo más caro. Afirmábamos una progresividad en el precio del agua ante comportamientos poco ecológicos. [4] También considerábamos que el consumo que marca cada contador no es un valor en sí para determinar si se consume de manera desproporcionada, hay que tener en cuenta el número de personas que toman agua de ese contador". Lo cual se resume sintéticamente así: "Igualdad y progresividad en el precio determinaban nuestra propuesta" (VC sept.-octubre 1998: 7, la cursiva es mía). 
RIS

REVISTA INTERNACIONAL DE SOCIOLOCIA

\section{POR LA DIGNIDAD CIVIL Y LA DEMOCRACIA PARTICIPATIVA}

La campaña de objeción fiscal en torno al recibo del agua ha sido, más allá del contenido de sus reivindicaciones concretas, una lucha por la dignidad civil y la democracia participativa según la autopercepción de sus dirigentes. Como tal, se puede considerar una expresión más, entre otras varias, de la emergencia de una nueva sociedad civil en la Cataluña del postfranquismo y la postransición. En sus reiteradas confrontaciones con las administraciones públicas (en manos de CiU, como la Generalitat, o del PSC-IC, como el Ayuntamiento de Barcelona y la EMMA), el movimiento vecinal topó con una actitud de insolencia y prepotencia sistemática. Los gestores públicos difícilmente ocultaban su desprecio hacia unos vecinos (de clase obrera, mayoritariamente inmigrantes del resto de España, políticamente derrotados, socialmente marginados y económicamente golpeados por la crisis) a quienes sólo estaban dispuestos a reconocerles el derecho a la protesta y la manifestación. No estaban, en cambio, dispuestos a verlos como protagonistas activos, como valedores de iniciativas y propuestas técnica y jurídicamente bien elaboradas y cargadas de justificaciones legales y morales perfectamente válidas, así mismo, de hecho, mejor justificadas que las de los políticos y tecnócratas de las administraciones. La crisis de la Plataforma acaecida en 1994, con la deserción de todas las organizaciones mencionadas antes, acentuó aun más el desprecio.

Probablemente, la duración increíble y sorprendente (diez años) del enfrentamiento tenga que ver con la obstinación de las dos partes en conflicto. Por el lado del poder político, el desprecio hacia la población movilizada, agravada por la volubilidad de los criterios aplicados en el recibo del agua. Por el lado de los vecinos movilizados, no sólo la voluntad de defender su bolsillo, sino también el deseo de restablecer la dignidad herida de un sector de la población reiteradamente golpeado y agraviado 7 . En su discurso del 20 de octubre de 1996 ante la asamblea celebrada en el Palacio de los Deportes de Barcelona, el presidente de la CONFAVC, Alfredo Vela, lo expresaba con suma claridad:

\footnotetext{
${ }^{7}$ En la asamblea celebrada en el Palacio de Deportes de Barcelona el 20 de octubre de 1996 tuvo lugar un incidente revelador. Al tomar la palabra el dirigente vecinal Jordi Gasull dirigiéndose en catalán a los 9.000 asistentes, fue víctima de un fuerte y pertinaz abucheo que le obligó a cambiar al castellano. Este episodio puede interpretarse tal vez como un rechazo hacia unas administraciones catalanas contra las que se luchaba. Pero es más verosímil que fuera una reacción expresiva de una multitud de personas originarias de tierras de habla castellana que veian en la hegemonía institucional del catalán un agravio adicional que se añadía a los demás agravios. Poco antes había aparecido en Cataluña el "Foro Babel", que expresaba el malestar de algunos castellanoparlantes ante lo que ellos consideraban una discriminación contra el castellano, y que difundió una cierta hostilidad contra el catalán que rompía el consenso lingüistico logrado durante la transición y nunca discutido antes. Hay que tener presente que la inmensa mayoría de los protagonistas de la guerra del agua eran inmigrados o hijos de inmigrados.
} 
[...] estamos escribiendo una página importante en la historia del movimiento vecinal, y quizás — por qué no decirlo— de la historia de nuestro país. Estamos poniendo en cuestión algo más que el precio del agua. La lucha del agua, con el tiempo, ha llegado a ser la expresión concreta del malestar generalizado contra toda la clase de abusos que expolian cada día más la economía de los trabajadores (1).

[...] Pero no acaban ahí las cosas. Todo esto se hace sin dar la más mínima explicación, en un claro ejemplo de la falta de democracia en este país, en el que se nos sigue tratando como súbditos, sometidos a decisiones arbitrarias, y no como ciudadanos en los que recae la soberanía y el poder de participar y decidir. Y no es que no se nos pida opinión en un tema de tal envergadura, es que tampoco se nos informa, porque sabían de antemano el rechazo popular ante el abuso (2).

[...] Este es un ejemplo de que en este país un ciudadano sólo sirve para votar, pero nunca para decidir. $Y$ a eso ellos, nuestros gobernantes de poltrona, lo llaman democracia. Para nosotros, las Asociaciones de Vecinos, que, con casi 30 años de historia, hemos luchado y seguimos luchando, y que hemos sido cuna de muchos de estos políticos que ahora nos gobiernan, la democracia es otra cosa muy diferente: es la democracia del poder participativo y continuo del ciudadano, y no un cheque en blanco cada cuatro años (3).

[...] en estos años se nos sigue sin reconocer como interlocutores sociales; nos da igual que ese papel se lo quieran dejar única y exclusivamente a sindicatos, consumidores y empresarios. Mientras tengamos una base social como la que aquí se manifiesta [a la asamblea asistían unas 9.000 personas], no nos hacen falta reconocimientos, pero creemos que nuestra historia y nuestro trabajo ya no dejan lugar a dudas de que nos hemos hecho acreedores a él (11).

Las palabras en las que se expresaban de manera más contundente los agravios sociales de la base del movimiento aparecen al final del discurso:

[...] Pero también hemos de añadir que esta campaña se ha llevado a cabo en un contexto de agravios añadidos a una larga crisis que está castigando, muy particularmente, a los sectores populares (que las asociaciones de vecinos especialmente representamos).

A los vecinos y vecinas de nuestros barrios, además de padecer reducciones del salario directo, situaciones de precariedad laboral y de paro, prácticas ilegales de economía sumergida, etc., también nos quieren hacer soportar, cada vez más, reducciones drásticas de poder adquisitivo en lo que se denomina salario indirecto:

- Los ataques al sistema público de la Seguridad Social y de las futuras pensiones, incitándonos a nuevos gastos en planes de pensiones privados.

- Los ataques al sistema público de prestaciones sanitarias, que instauran dos clases de medicina, la de los ricos y la de los pobres.

- El aumento de la fiscalidad indirecta, que grava los productos y servicios básicos como el que hoy denunciamos del agua o mañana los residuos urbanos. 
- La desatención presupuestaria hacia el sistema educativo público, desde la guardería hasta la universidad.

- La liberalización y privatización del sector público que, bajo la excusa de la competitividad, nos deja a merced del beneficio de las grandes financieras, como es el caso del suministro eléctrico, del gas o telefónica.

- Una marcada tendencia a aplicar los presupuestos públicos a favor del beneficio empresarial y financiero, o en gastos suntuarios, desatendiendo los servicios básicos de las clases populares y pequeños contribuyentes, como por ejemplo transporte público y vivienda, que son claramente insuficientes (13-14) (DA 1996). ${ }^{8}$

\section{ALGUNAS CONSIDERACIONES SOCIOLÓGICAS SOBRE LAGUERRA DEL RECIBO DEL AGUA}

\section{De una actitud reactiva a otra proactiva}

El conflicto brotó como una actitud reactiva ante lo que se vivió como un abuso que vulneraba un interés económico inmediato. Inmediatamente, la agregación de múltiples protestas individuales idénticas las transforma en acción colectiva potencial, y las somete a una elaboración que las convierte en colectivas, pero también en universalistas. Las protestas dejan de ser una mera pugna distributiva en torno a conceptos aceptados como legítimos por ambas partes; el enfrentamiento se traslada, justamente, a la discusión de los conceptos o contenidos mismos que son objeto del conflicto. Se discute la cuantía a pagar, pero también la justificación y la legitimidad de cada partida. Los dirigentes ponen unánimemente mucho énfasis desde el comienzo en que no se trata de un movimiento anti-impuestos, o sea - cabe añadir-, demagógico y qualunquista; y cuando se lanza la objeción fiscal, explican insistentemente a los participantes que, cuando se negocie con las administraciones cuáles son los impuestos justos y a cuánto ascienden, estos impuestos deberán pagarse (aunque se negocie una rebaja de los mismos).

El movimiento va configurándose muy pronto, como una protesta no particularista ni corporativa, sino orientada a redefinir las reglas del juego y los términos del problema con unos criterios objetivos y universales. Esto le da una dimensión política, no sólo porque los destinatarios de la protesta e interlocutores del movimiento son autoridades políticas, sino también porque el contenido de la protesta es la definición de la fiscalidad. Lo que se discute son criterios de

\footnotetext{
${ }^{8}$ Los números entre paréntesis indican las páginas del documento que contiene el discurso (DA 1996).
} 
aplicación de los tributos o impuestos: si han de ser proporcionales al consumo de agua, si tienen que haber tarifas desincentivadoras del despilfarro de agua, si las tarifas han de tomar en consideración el número de habitantes de cada hogar, etc. En suma, el conflicto, iniciado en orden disperso por vecinos individuales como reacción ante una supuesta arbitrariedad, y por lo tanto como defensa aparentemente inmediata de intereses económicos individuales, se transforma en el curso de su desarrollo en una lucha proactiva, propositiva y universalista, rasgo que se refuerza con una explícita aspiración democrática participativa y, por tanto, con una reivindicación de la ciudadanía.

\section{Las Asociaciones de Vecinos como capital social de la población}

Las AAVV aparecen como un capital social con que cuentan los vecinos. La noción de "capital social" comporta la existencia de unos marcos estructurados y unos vínculos de confianza, basados en experiencias anteriores. Véase lo que dice James Coleman al respecto: "El capital social se define por su función. No es una entidad singular sino una variedad de entidades distintas con dos elementos en común: todas ellas contienen alguna dimensión de las estructuras sociales, y todas ellas facilitan ciertas acciones de los actores [...] dentro de las estructuras. Al igual que otras formas de capital, el capital social es productivo, haciendo posible la consecución de determinados fines inalcanzables sin él" (2001: 51). Hablando de los círculos clandestinos de estudiantes de Corea del Sur señala algo que se aplica exactamente al caso de la guerra del recibo del agua: "estos grupos constituyen un recurso que facilita el tránsito desde la protesta individual a la revuelta organizada" (ibid.: 55). El capital social, según este autor, "existe en las relaciones entre las personas", y reside en la fiabilidad y la confianza. Robert Putnam tiene un enfoque algo diferente: el capital social, para él, "se refiere a las características de la organización social, como por ejemplo redes, normas y confianza, que facilitan la cooperación y la coordinación en beneficio mutuo" (2001: 90).

Los vecinos descontentos no van a protestar a la compañía de aguas ni al ayuntamiento, sino que empiezan dirigiéndose a la Asociación de Vecinos. Esto puede interpretarse en el sentido de que los vecinos entienden dos cosas: (1) que la negociación con la empresa y las administraciones será difícil y conflictiva, razón por la cual conviene unirse y organizarse, y (2) que el marco "natural" de unión de los vecinos son las asociaciones de vecinos. En efecto, los activistas y dirigentes vecinales no son vistos - a diferencia de los funcionarios de la administración, es decir, los políticos en puestos de mando, y de los portavoces de las empresas - como un poder ajeno, como una autoridad superpuesta, ni como "delegados" o "representantes" separados de ellos, sino como unos vecinos más, que forman parte "de los suyos" y prestan servicios a los demás vecinos en forma voluntaria y gratuita. 
RIS

REVISTA INTERNACIONAL DE SOCIOLOGIA

№ 38, MAYO-AGOSTO, 2004

"[Yo] no era - dice AN- como los políticos y sindicalistas que llegaban a los barrios a dormir y se olvidaban de todo." Este dirigente vecinal del Buen Pastor (barrio de la capital catalana) era a la vez dirigente sindical: perteneció a la dirección del Sindicato del Metal de CCOO de Cataluña; pero decidió colocar el activismo vecinal en el centro de gravedad de su militancia. Por su parte MP, dirigente de L'Hospitalet, que llega a la lucha también desde la política y el sindicalismo, valora mucho la significación y la especificidad del movimiento vecinal. En los años 70 las AAVV "eran el lugar que los militantes políticos usaban como plataforma de expresión". Pero "a lo largo del tiempo he ido comprobando que el movimiento vecinal sigue manteniendo un cierto [grado] de independencia de los partidos políticos; está muy en contacto con la realidad social que le rodea, con el barrio y la ciudad, y de alguna manera es [el movimiento] más cercano y el que mejor entiende al vecino o vecina y el que puede [expresar] y organizar el malestar o la inquietud" de la gente [MP 2]. "Las dificultades han sido enormes - dice JR, activista del Ensanche barcelonés-, y se ha conseguido algo que ni las administraciones podían creer, ni la compañía de aguas, ni los propios políticos parlamentarios, tanto los que están arriba como los de la oposición. Yo creo que es un ejemplo, una lección [...] que ha dado la sociedad civil” [JR 1].

Las AAVV aparecen como las estructuras de movilización más directas que la población tiene a su alcance. "La movilización de redes sociales preexistentes -dice Sydney Tarrow a propósito de este tipo de estructuras- reduce los costes sociales transaccionales de la convocatoria de las manifestaciones, y mantiene unidos a los participantes incluso una vez que el entusiasmo inicial de la confrontación se ha desvanecido. [Esto] es lo que hace posible la transformación de la acción colectiva episódica en movimientos sociales" (1997: 56). Se trata de estructuras, dotadas de una organización y una experiencia acumulada, que hacen posible reducir los costes de la acción colectiva y facilitan el acuerdo y la acción. Es muy significativo - y confirma esta apreciación - que cuando en octubre de 1994 las restantes organizaciones de la Plataforma unitaria se desvinculan de la campaña por considerar que la respuesta de las administraciones públicas es satisfactoria, la fuerza del movimiento no se reduce en absoluto. La lucha prosigue como si no hubiese ocurrido nada porque las estructuras de movilización mantienen sus vinculos iniciales con la población movilizada, aunque con la pérdida de irradiación social ya mencionada.

Las AAVV, a la vez que se vinculan muy estrechamente con la población afectada, agrupan a una elite provista de más recursos (información, relaciones - por ejemplo, facilidad de acceso a abogados, políticos, periodistas, especialistas y técnicos-) que el vecino corriente. Esto las convierte en actores privilegiados, capaces de formular definiciones y justificaciones de las acciones a emprender. Ayudan a imaginar, discutir, acordar y llevar a la práctica las recogidas de firmas, las manifestaciones, los cortes de tráfico, la objeción fiscal (incluso en sus aspectos prácticos) y el diálogo con los interlocutores institucionales. Las AAVV repre- 
sentan el principal recurso movilizador y actúan como intelectuales orgánicos colectivos de la población movilizada, en toda la amplia gama de funciones propias del "intelectual orgánico" en el sentido gramsciano.

\section{Incorporación de elementos de sostenibilidad ecológica en la lucha}

La valoración por los dirigentes vecinales de la toma de consciencia ecológica respecto de los problemas ligados al agua no siempre es coincidente. Algunos opinan que no ha penetrado prácticamente nada en la gran masa de los protagonistas, aun admitiendo que sí lo ha hecho en personas del núcleo dirigente. Otros opinan lo contrario.

El presidente de la AV del barrio del Buen Pastor (Barcelona) dice que la campaña consiguió que los vecinos y vecinas fueran a las asambleas y escucharan "cosas que, si no hubiese sido por la campaña del agua, hubiese sido muy difícil que se interesaran por ellas" [AN 4]. Y el presidente de la Federación de AAVV de L'Hospitalet afirma: "hoy yo creo que cualquier vecino que haya participado en la campaña del agua se le puede hablar del tema, porque entiende, comprende, sabe lo que es la TAMGREM [tasa de la basura]'[MP 7].

Parece que, poco o mucho, los participantes han tenido que reflexionar sobre el coste del agua y su depuración y suministro, y sobre el tratamiento de los residuos sólidos urbanos.

También parece claro que no fue una movilización que pueda caracterizarse como medioambiental. Los objetivos predominantes fueron otros: luchar contra los abusos de administraciones públicas y empresas de servicio, por la transparencia en la fiscalidad, y por la participación ciudadana en temas - como los criterios de la fiscalidad- que no suelen estar en el orden del día del debate político.

\section{EPÍLOGO: EL FINAL DE LA GUERRA DEL RECIBO DEL AGUA}

En el otoño de 2002, el vicepresidente de la FAVB, Andrés Naya, publicaba en $L a$ Veu del Carrer un balance de la lucha recién terminada. Señalaba que la huelga fiscal supuso para las distintas administraciones públicas implicadas un recorte de unos 27 millones de euros en impuestos. En lugar de la deuda impagada de 37,67 millones de euros, aceptaron ingresar sólo 10,83 millones, es decir, un $28,7 \%$ del total. En un momento dado del conflicto, cuando habían pasado ya unos años de impago, el movimiento vecinal había exigido una rebaja que estableció en un $46 \%$, alegando que la magnitud de la deuda y la desmesurada prolongación del conflicto se debían a la irresponsabilidad de las administraciones. "A la hora de 
RIS

REVISTA INTERNACIONAL DE SOCIOLOCIA

pactar el final de la protesta [a comienzos de 2002], la Generalitat aceptó la rebaja, pero se negó a aprobar un decreto de amnistía parcial que recogiese este descuento y la anulación de la deuda total o parcial a las familias más pobres, así como la posibilidad de pagar el resto en plazos de ocho años en pequeñas cuotas anuales. Aprobar el decreto implicaba reconocer públicamente alguna responsabilidad política en el largo conflicto, y para evitarlo se optó por la puerta de atrás: el acuerdo del $46 \%$ de descuento se materializó buscando coartadas administrativas. Es decir, buscando algún error cometido en los trámites de cobro o en las notificaciones que permitiese reducir la deuda, como mínimo, hasta las cantidades acordadas." Este confuso procedimiento ha desembocado en el cobro de una cantidad bastante inferior a la pactada. El dirigente vecinal concluye así: "La rebaja de impuestos es tan importante que muchas familias han recibido descuentos reales de entre el 50 y el $80 \%$. Una amnistía encubierta y un triunfo vecinal, digan lo que digan las administraciones" (VC sept.-octubre 2002: 7).

\section{REFERENCIAS DOCUMENTALES Y BIBLIOGRÁFICAS}

DA (1996), Documento que lleva por título "Asamblea [del recibo del] agua [de] 20 de octubre de 1966”, que contiene el discurso de Alfredo Vela; publicación interna del movimiento.

VC La Veu del Carrer, publicación mensual de la FAVB, se cita según el mes y año de publicación.

ARCS [Anàlisi i Recerca en Ciències Socials] (2002), La campanya de l'aigua. Deu anys de mobilització ciutadana, Barcelona, Fundació Jaume Bofill.

CASTELLS, M. (1997), Movimientos sociales urbanos, Madrid, Siglo XXI.

COLEMAN, J. S. (2001), “Capital social y creación de capital humano”, Zona Abierta, n 94/95, pp. 47-82.

JANOSKI, Th. (1998), Citizenship and Civil Society. A Framework of Rights and Obligations in Liberal, Traditional, and Social Democratic Regimes, Cambridge, Cambridge University Press.

KRIESI, H. (1999), "La estructura organizacional de los nuevos movimientos sociales en su contexto político", en D. McAdam, J. McCarthy y M. Zald (eds.) (1999), Movimientos sociales perspectivas comparadas, Madrid, Ediciones Istmo, pp. $221 \mathrm{ss.}$

KRIESI, H., R. KOOPMANS, J.W. DUYVENDAK y M.G. GIUGNI (1998), New Social Movements in Western Europe. A Comparative Analysis, Minneapolis, University of Minnesota Press, Minneapolis.

KYMLICKA, W. y W. NORMAN (1995), "Return of the Citizen: A Survey of Recent Work on Citizenship Theory", en R. Beiner, (ed.) Theorizing Citizenship, Nueva York, State University of New York Press, pp. 285-315. 
LARAÑA, E. y J. GUSFIELD (eds.) (1994), Los nuevos movimientos sociales. De la ideología a la identidad, Madrid, CIS.

MARTÍNEZ GIL, J. (2001), Propuestas para la gestión y el uso adecuado del agua, CODA

McADAM, D., J. McCARTHY y M. ZALD (eds.) (1999), Movimientos sociales: perspectivas comparadas, Madrid, Ediciones Istmo.

McCARTHY, J. y M. ZALD (1977), "Resource Mobilization and Social Movements: a Partial Theory", American Journal of Sociology, vol. 82, pp. 1212-1241

MELUCCI, A. (1988), "Social Movements and the Democratization of Everiday Life", en J. Keane, (ed.), Civil Society and the State. New European Perspectives, Londres, University of Westminster Press, pp. 245-260

MENA AYUSO, E. (1999), "Desobediencia civil: la 'lucha del agua”, Trabajo final de carrera, Licenciatura de Sociología, Facultad de Económicas, Universidad de Barcelona (director: Juan A. Mellón)

PUTNAM, R.D. (2001), "La comunidad próspera. El capital social y la vida pública", Zona Abierta, núm. 94/95, pp. 89-104.

RECIO, A. (1993), "Movimiento urbano, ecología e intereses sociales: experiencias de la Barcelona postolímpica", Mientras tanto, núm. 54 (mayo-junio)

TARROW, S. (1997), El poder en movimiento. Los movimientos sociales, la acción colectiva y la politica, Madrid, Alianza.

TELLO, E. (1994), "El recibo del agua en Barcelona: lecciones para una fiscalidad ecológica y equitativa" [nota editorial, firmada 'E.T.'], Mientras tanto, n' 58 (verano).

THOMPSON, E.P. (1979), Tradición, revuelta y consciencia de clase, Barcelona, Crítica.

YSA, T. (1997), "Estudio de caso: La acción colectiva anti-canon del agua". Trabajo final de carrera, Licenciatura de Sociología, Facultad de Económicas, Universidad de Barcelona (director: Salvador Aguilar) 